\title{
Oxycodone versus Fentanyl for Intravenous Patient-Controlled Analgesia after Laparoscopic Gynecologic Surgery
}

\author{
Nan Seol Kim, Ji Eun Kim \\ Department of Anesthesiology and Pain Medicine, Soonchunhyang University Chenona Hospital, Cheonan, Korea
}

\begin{abstract}
Objective: Oxycodone, a semi-synthetic thebaine derivative opioid, is commonly used for treating moderate to severe pain. The aim of this study was to compare the efficacy and side effects of oxycodone and fentanyl used for treating postoperative pain with intravenous patient-controlled analgesia (IV-PCA) after laparoscopic gynecologic surgery.

Methods: A total of 122 patients were randomized to receive postoperative pain treatment with either oxycodone $(n=62$, group 0$)$ or fentanyl ( $\mathrm{n}=60$, group F). Patients received $7.5 \mathrm{mg}$ oxycodone and $150 \mathrm{mcg}$ fentanyl with ketorolac $30 \mathrm{mg}$ at the end of anesthesia, and then continued with IV-PCA (conversion dose ratio, 50:1) for 48 hours postoperatively. A blinded observer assessed postoperative pain based on a numerical rating scale, postoperative nausea and vomiting and other side effects, infused PCA dose, patient satisfaction, and sedation level.

Results: No significant differences were observed in patient satisfaction according to the analgesic used during the 48 hours postoperative period.

Conclusion: Oxycodone showed similar efficacy for pain relief compared to fentanyl when used at a conversion dose ratio of 50:1.

Therefore, oxycodone may be useful as an alternative to fentanyl for IV- PCA after laparoscopic gynecologic surgery.
\end{abstract}

Keywords: Fentanyl; Oxycodone; Postoperative pain

\section{INTRODUCTION}

Recent advances in surgery and anesthesia have led to a significant reduction in severe postoperative complications. However, patients have a higher need for comfortable anesthesia management with minimal postoperative side effects. Among common symptoms occurring after surgery, postoperative nausea and vomiting (PONV, 49\%) and postoperative pain (27\%) are the two most important concerns for patients recovering after surgery [1].

Various methods have been used to control postoperative pain; among them, intravenous patient-controlled analgesia (IV-PCA) has been commonly applied because it has high pain relief efficacy with minimal side effects [2]; it has been reported that IV-PCA is associated with higher analgesic efficacy and patient satisfaction levels than conventional methods [3].

In general, laparoscopic surgery has several advantages including decreased postoperative pain, faster recovery, and better cos- metic effects compared to laparotomy [4]. However, there have been many cases of moderate pain after minor laparoscopic surgery due to minimal use of analgesics [5]. In addition, patients undergoing laparoscopic gynecologic surgery are at high risk of PONV and are more likely to complain of pain than those undergoing general surgery; PCA may be interrupted due to PONV. Therefore, when IV-PCA is used after laparoscopic gynecologic surgery (which is relatively minor), it is important to select appropriate analgesic agents and adjust the dose and lockout interval to obtain satisfactory analgesic effects while reducing side effects such as PONV.

In Korea, fentanyl is the opiate most commonly used as an analgesic agent for IV-PCA after surgery. In 2013, IV-dihydrohydroxycodeinone (oxycodone) was approved for IV-PCA by the Ministry of Food and Drug Safety and released to the market [6]. Oxycodone is a semisynthetic analgesic opioid made from thebaine (derived from poppy), which acts on $\mu$-opioid receptors to relieve 
mild to severe pain [7]. If oxycodone is used in excess or in opioidsensitive patients, there is a risk of respiratory depression, bradycardia, apnea, hypotension, circulatory insufficiency, respiratory arrest, and death, as well as minor side effects such as PONV [6]. Therefore, it is important to establish a safe dose for the direct conversion factor of fentanyl and oxycodone, which are the most commonly used analgesic agents in IV-PCA.

When IV oxycodone was first introduced, a conversion dose ratio of 1:100 between fentanyl and oxycodone was recommended. However, several studies have instead recommended a conversion ratio of 1:75 [8,9], while others recommended a ratio of 1:60 [10,11]. When using a conversion dose ratio of 1:60, the analgesic effect was similar but the PCA consumption of oxycodone was less than that of fentanyl [10]; at a ratio of 1:60, there was a difference in the analgesic effect between the two groups [11]. Therefore, we hypothesized that the conversion dose ratio between fentanyl and oxycodone could be decreased to 1:50 in this study.

The purpose of this study was to compare the analgesic effect, PCA usage, side effects (including PONV), and patient satisfaction, at a 1:50 conversion dose ratio, between fentanyl and oxycodone, which are the analgesic agents most commonly used for IVPCA after laparoscopic gynecologic surgery at Soonchunhyang University Cheonan Hospital.

\section{MATERIALS AND METHODS}

This study was approved by the Institutional Review Board of Soonchunhyang University Cheonan Hospital (IRB approval no., 2016-06-013) and registered on the International Clinical Trials Registry Platform (http://cris.nih.go.kr, KCT 0002275). A total of 130 adult patients aged 18 to 65 years, with an American Society of Anesthesiologists (ASA) physical status of 1 or 2 and who had requested postoperative IV-PCA for laparoscopic gynecologic surgery scheduled at our hospital, were included in this study. Patients with a history of bleeding, hepatitis, or renal failure; those with habitual sedative or other drug use; those with psychiatric disease; and those who were inappropriate candidates for IV-PCA were excluded.

On the day before surgery, patients were informed of the purpose of the study, and the PCA method, numerical rating scale (NRS), and possible side effects of the two forms of IV-PCA were discussed. All patients included in the study provided written informed consent, after which they were randomly allocated to either the fen- tanyl (fentanyl citrate; Guju, Seoul, Korea) group (group F, n=60) or the oxycodone (OxyNorm; Mundipharma, Seoul, Korea) group (group $\mathrm{O}, \mathrm{n}=62$ ). Group allocation was performed by a blinded observer according to a computer-generated randomization code.

On the morning before the operation, vascular access was secured using an $18 \mathrm{G}$ needle. Patients were transported to the operation room without pre-anesthetic medication. Upon arrival, they were connected to an electrocardiograph, a non-invasive blood pressure monitor, and a pulse oximeter. Anesthesia was induced by IV injection of $2 \mathrm{mg} / \mathrm{kg}$ propofol and $0.8 \mathrm{mg} / \mathrm{kg}$ rocuronium bromide (Rocnium; Hanil-pharm, Seoul, Korea). Following endotracheal intubation, oxygen and air were supplied at a fraction of inspired oxygen of 0.4 together with desflurane (end-tidal concentration of 6.0-7.0 vol\%), maintaining an end-tidal carbon dioxide level of 35-40 mm Hg. The desflurane concentration was controlled so that blood pressure and heart rate values were held within $20 \%$ of the preoperative measurements; $0.5-1 \mu \mathrm{g} / \mathrm{kg}$ fentanyl was used for analgesia as necessary. Dexamethasone $5 \mathrm{mg}$ was injected IV immediately after induction of anesthesia to prevent PONV. All surgeries were performed by the same surgeon. After completing the operation, desflurane and air were discontinued. Pyridostigmine and glycopyrrolate were injected to reverse the muscle relaxation, and reversal was confirmed by a more than $90 \%$ response during train-of-four monitoring of the ulnar nerve. Patients were extubated after verifying recovery of consciousness and spontaneous respiration. The IV-PCA device (Ambix Anapa; IWha-Fresenius Kabi, Seoul, Korea) was then connected. Patients in group F were injected with a loading dose of $150 \mu \mathrm{g}$ of fentanyl and $30 \mathrm{mg}$ of ketorolac, and those in group $\mathrm{O}$ with $7.5 \mathrm{mg}$ of oxycodone and $30 \mathrm{mg}$ of ketorolac. All patients were administered $0.3 \mathrm{mg}$ of ramosetron to prevent PONV, the most common side effect of IV-PCA. For group F patients, $700 \mu \mathrm{g}$ of fentanyl, $150 \mathrm{mg}$ of ketorolac, and 0.6 $\mathrm{mg}$ of ramosetron were mixed with saline to a total volume of 100 $\mathrm{mL}$; continuous infusion was set to $14 \mu \mathrm{g} / \mathrm{hr}$ of fentanyl, a bolus dose of $0.5 \mathrm{~mL}$, and a lockout interval of 15 minutes. For group $\mathrm{O}$, based on a fentanyl-oxycodone conversion dose ratio of 1:50, 35 $\mathrm{mg}$ of oxycodone, $150 \mathrm{mg}$ of ketorolac, and $0.6 \mathrm{mg}$ of ramosetron were mixed with saline to a total volume of $100 \mathrm{~mL}$; continuous infusion was set to $0.7 \mathrm{mg} / \mathrm{hr}$ of oxycodone, with a bolus dose of $0.5 \mathrm{~mL}$ and a 15 -minute lockout interval. These settings were maintained for 48 hours. The study was double-blinded regarding the type of IV-PCA. Upon arrival to the post-anesthesia care unit (PACU), and at $0.5,2,8,24$, and 48 hours after laparoscopic gyne- 
cologic surgery, the quantity of analgesics used by each patient, the administration of additional analgesics, pain intensity, sedation level, and side effects (including PONV) were assessed and the data were recorded by a single blinded observer.

The pain intensity was assessed by the NRS, on which a score of '0' corresponds to 'no pain' and '100' to 'worst pain imaginable.' In patients with an NRS score between 30 and 50 (representing moderate pain), if the established dose of analgesics was injected and further pain control was requested, an additional IV injection of $30 \mathrm{mg}$ of ketorolac was administered. In group F, patients with an NRS score $\geq 50$ (representing high-intensity pain) who requested further pain control were treated with an additional IV injection of $1 \mu \mathrm{g}$ fentanyl per $\mathrm{kg}$. In group $\mathrm{O}$, patients with an NRS score $\geq 50$ (representing high-intensity pain) who requested further pain control were treated with an additional IV injection of 0.05 mg oxycodone per $\mathrm{kg}$.

The sedation level was assessed using the Modified Observer's Assessment of Alertness/Sedation (MOAA/S) scale (0, does not respond to noxious stimuli; 1 , does not respond to mild prodding or shaking; 2 , responds only after mild prodding or shaking; 3 , re- sponds only after name is called loudly or repeatedly; 4 , lethargic response to name spoken in normal tone; and 5, responds readily to name spoken in normal tone). Respiratory depression was defined as a respiratory rate of $<8$ breaths per minute. In patients with a MOAA/S scale score $\leq 1$, and in those with respiratory depression, PCA was immediately stopped and $0.01 \mathrm{mg}$ naloxone $/ \mathrm{kg}$ was injected IV. Other side effects (PONV, dizziness, pruritus, and headache) were monitored. Patients with severe PONV received an additional IV injection of $10 \mathrm{mg}$ of metoclopramide. Those with pruritus were IV-injected with $25 \mathrm{mg}$ of pheniramine.

Patient satisfaction, graded as very satisfied, satisfied, neutral, or dissatisfied, was measured at 8 and 48 hours postoperatively.

The required number of patients was determined based on a previous study [12]. The primary endpoint was the NRS score at 30 minutes postoperatively. The clinically significant effect size was an average primary endpoint difference between the two groups of 7.5, with a standard deviation of 15.28. With a significance level $(\alpha)$ of 0.05 (one-sided) and power (1- $\beta$ ) of $0.8,52$ patients were required for each group according to the power calculation. With an expected dropout rate of $10 \%$, the final number of

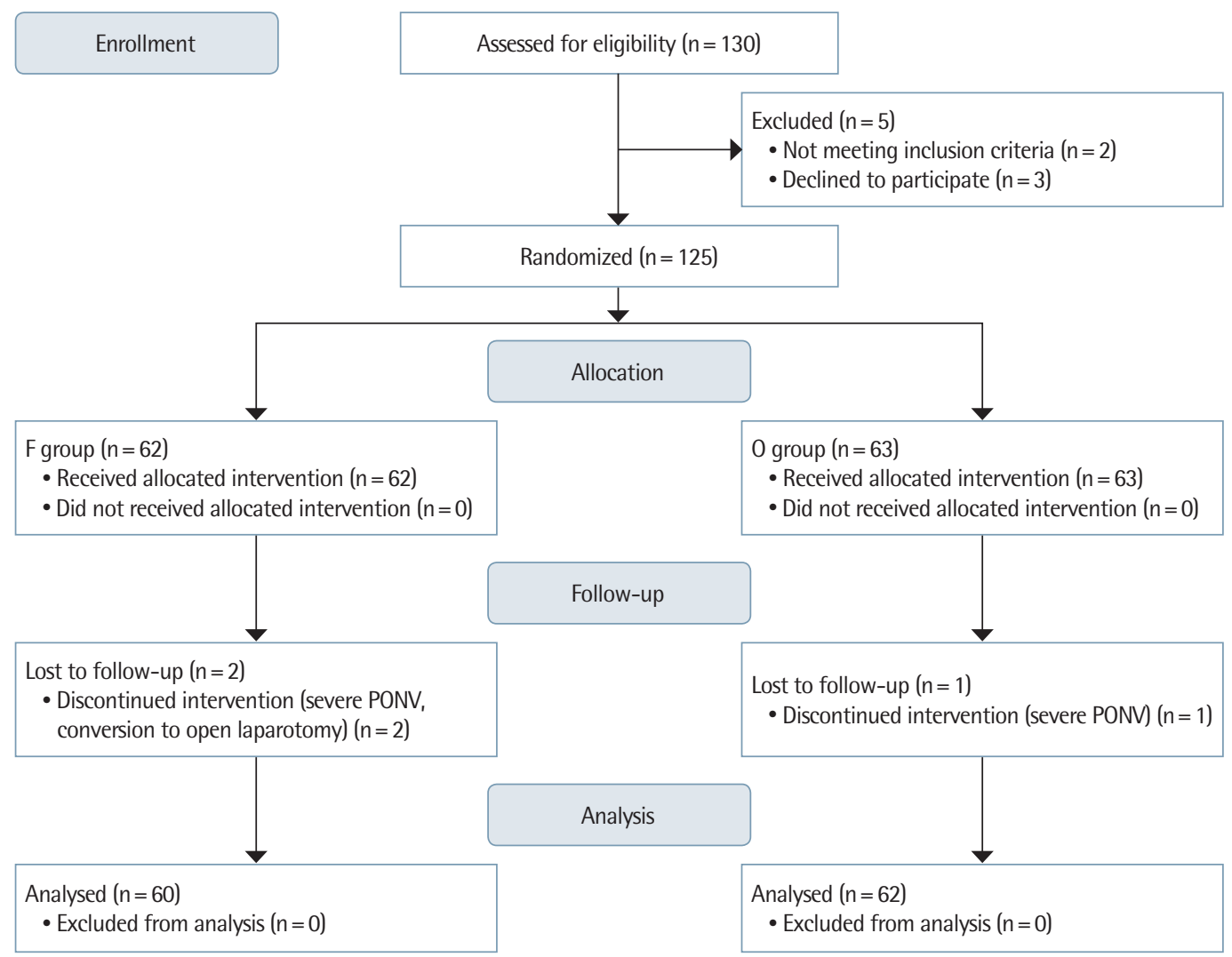

Fig. 1. CONSORT flow diagram. F group, fentanyl group; 0 group, oxycodone group. 
participants estimated to be required in each group was 65 .

Statistical analysis was performed using PASW SPSS software for Windows ver. 18.0 (SPSS Inc., Chicago, IL, USA). Data are expressed as the mean and standard deviation. Demographic data were analyzed using Pearson's $\chi^{2}$ test or Student t-test. The generalized estimating equation method was used to compare IV-PCA quantity and pain level between the two groups for 48 hours postoperatively, both at rest and during coughing. A P-value less than 0.001 was considered significant. The incidence of side effects and degree of patient satisfaction were compared between groups $\mathrm{F}$ and $\mathrm{O}$ using Pearson's $\chi^{2}$ test or Fisher's exact test. A P-value less than 0.05 was considered significant.

\section{RESULTS}

A total of 130 patients were screened, among whom 125 were enrolled in the study, were divided randomly into two groups. Of the study patients, two in group $\mathrm{F}$ and four in group $\mathrm{O}$ were excluded from the study. The data of the remaining 122 patients were analyzed, with 60 patients in group $\mathrm{F}$ and 62 patients in group $\mathrm{O}$ (Fig. 1).

There were no significant differences between the two groups in age, height, body weight, operation time, anesthesia time, ASA physical status, amount of fluid injected during surgery, motionsickness, or smoking history (Table 1). Group O showed a significantly lower level of PCA consumption than Group F at 0-48 hours after surgery (Fig. 2).

In terms of pain at rest based on the NRS, group O showed a significantly lower level upon arrival to the PACU, but there was no

Table 1. Demographic data and anesthesia characteristics of the patients

\begin{tabular}{lccc}
\hline Characteristic & Group $\mathrm{F}(\mathrm{n}=60)$ & Group 0 $(\mathrm{n}=62)$ & P-value \\
\hline Age $(\mathrm{yr})$ & $44.4 \pm 5.7$ & $45.4 \pm 8.2$ & 0.431 \\
ASA physical status I/II & $47 / 13$ & $43 / 19$ & 0.260 \\
Nonsmoker & $55(91.7)$ & $57(91.9)$ & 0.957 \\
History of motion sickness or PONV & $22(36.7)$ & $19(30.6)$ & 0.481 \\
Height $(\mathrm{cm})$ & $158.6 \pm 5.4$ & $156.1 \pm 13.6$ & 0.196 \\
Weight $(\mathrm{kg})$ & $59.4 \pm 9.2$ & $29.1 \pm 8.8$ & 0.853 \\
Body mass index $\left(\mathrm{kg} / \mathrm{m}^{2}\right)$ & $23.6 \pm 3.1$ & $23.8 \pm 3.4$ & 0.664 \\
Total fluid $(\mathrm{mL})$ & $406.7 \pm 143.9$ & $395.2 \pm 201.0$ & 0.716 \\
Duration of surgery $(\mathrm{min})$ & $77.0 \pm 29.3$ & $72.0 \pm 21.7$ & 0.288 \\
Duration of anesthesia $(\mathrm{min})$ & $101.4 \pm 30.6$ & $96.5 \pm 22.6$ & 0.309 \\
\hline
\end{tabular}

Values are presented as mean \pm standard deviation or number of patients (\%). There were no significant differences between the two groups (group F, fentanyl group; group 0, oxycodone group).

ASA, American Society of Anesthesiologists; PONV, postoperative nausea and vomiting. significant difference between the two groups at 30 minutes, 2 hours, 8 hours, 24 hours, or 48 hours after surgery (Fig. 3). For coughing, the two groups did not show any significant difference on the NRS (Fig. 4).

There was no significant difference in terms of PONV incidence between the two groups (Table 2). In addition, the rate of additional use of rescue analgesics and antiemetics was not significantly different between the two groups (Table 3). There was no signifi-

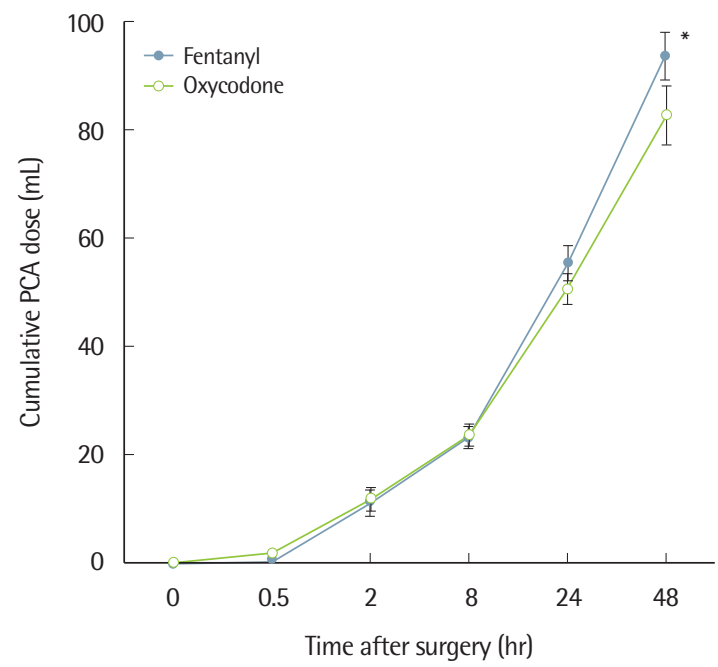

Fig. 2. Accumulated fentanyl and oxycodone consumption $(\mathrm{mL})$ at 0-48 hours postoperatively. Values are presented as mean \pm standard deviation. P-value is calculated using the generalized estimating equation method. PCA, patientcontrolled analgesia. ${ }^{*} \mathrm{P}<0.001$ for the interaction effect between group and time.

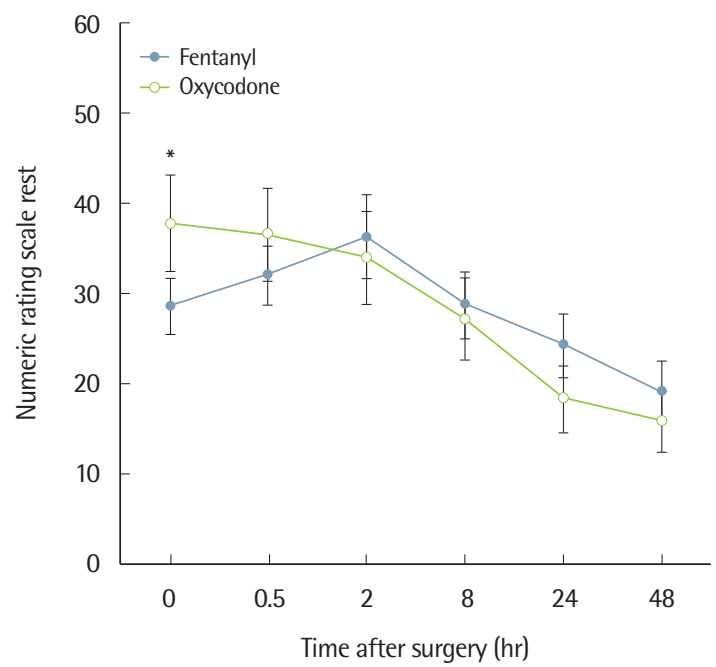

Fig. 3. Numeric rating scale $(0-100 \mathrm{~mm})$ score at rest 0-48 hours postoperatively. Values are presented as mean \pm standard deviation. P-value is calculated using the generalized estimating equation method. ${ }^{*} \mathrm{P}<0.001$ for the interaction effect between group and time. 
cant difference between the two groups in terms of other side effects such as dizziness, drowsiness, headache, pruritus, constipation, or respiratory depression (Table 4). There was no significant difference in sedation scores between the two groups (Fig. 5). Finally, there was no significant difference in patient satisfaction

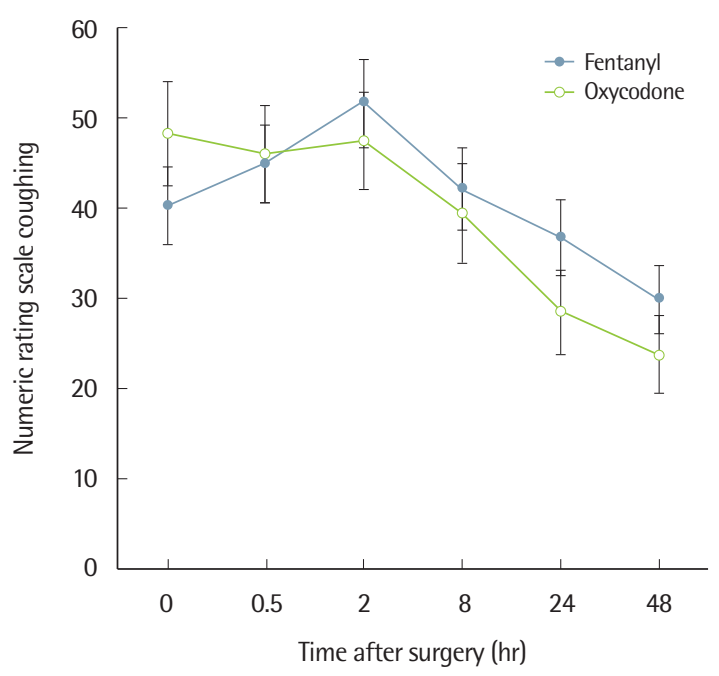

Fig. 4. The numeric rating scale score when coughing at 0-48 hours postoperatively. Values are presented as mean \pm standard deviation. P-value is calculated using the generalized estimating equation method. $P<0.001$ for the interaction effect between group and time.

Table 2. Incidence (\%) of postoperative nausea and vomiting

\begin{tabular}{|c|c|c|c|c|c|c|}
\hline \multirow{2}{*}{$\begin{array}{l}\text { Time after } \\
\text { surgery (hr) }\end{array}$} & \multicolumn{2}{|c|}{ Group F $(n=60)$} & \multicolumn{2}{|c|}{ Group 0 ( $n=62)$} & \multicolumn{2}{|c|}{ P-value } \\
\hline & Nausea & Vomiting & Nausea & Vomiting & Nausea & Vomiting \\
\hline 0 & $1(1.7)$ & 0 & $1(1.6)$ & $1(1.6)$ & 1.000 & 1.000 \\
\hline 0.5 & $7(11.7)$ & 0 & $6(9.7)$ & 0 & 0.722 & - \\
\hline 2 & $7(11.7)$ & $2(3.3)$ & $9(14.5)$ & 0 & 0.641 & 0.240 \\
\hline 8 & $4(6.7)$ & $1(1.7)$ & $7(11.3)$ & 0 & 0.530 & 0.492 \\
\hline 24 & $5(8.3)$ & $2(3.3)$ & $4(6.5)$ & 0 & 0.741 & 0.240 \\
\hline 48 & $2(3.3)$ & $2(3.3)$ & $3(4.8)$ & 0 & 1.000 & 0.240 \\
\hline
\end{tabular}

Values are presented as number of patients (\%).

Group F, fentanyl group; Group 0, oxycodone group. measured at 2 and 48 hours after surgery between the two groups (Table 5).

\section{DISCUSSION}

Opioids, which are commonly used for IV-PCA, are full $\mu$-receptor binding agonists that do not have an analgesic ceiling effect

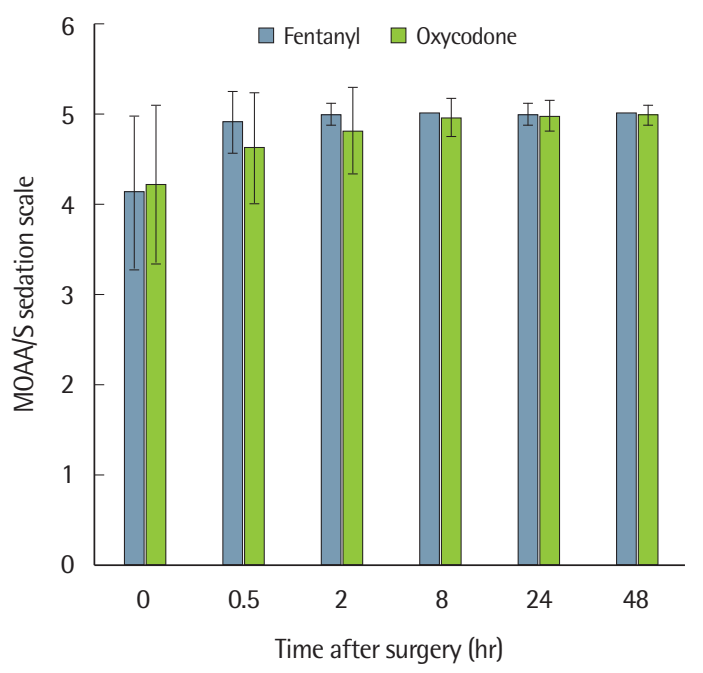

Fig. 5. Modified Observer's Assessment of Alertness/Sedation (MOAA/S) scale.

Table 4. Incidence (\%) of adverse events

\begin{tabular}{lccc}
\hline Variable & Group $F(n=60)$ & Group 0 $(n=62)$ & P-value \\
\hline Dizziness & $22(36.7)$ & $14(22.6)$ & 0.088 \\
Drowsiness & $7(11.7)$ & $18(29.0)$ & 0.018 \\
Headache & $9(15.0)$ & $8(12.9)$ & 0.738 \\
Pruritus & 0 & $1(1.6)$ & 1.000 \\
Constipation & $1(1.7)$ & 0 & 0.488 \\
Respiratory depression & $1(1.7)$ & 0 & 0.488 \\
\hline
\end{tabular}

Values are presented as number of patients (\%).

Group F, fentanyl group; Group 0, oxycodone group.

Table 3. Use of rescue analgesics and antiemetics

\begin{tabular}{|c|c|c|c|c|c|c|}
\hline \multirow{2}{*}{ Time after surgery (hr) } & \multicolumn{2}{|c|}{ Group $F(n=60)$} & \multicolumn{2}{|c|}{ Group 0 ( $n=62)$} & \multicolumn{2}{|c|}{ P-value } \\
\hline & Analgesics & Antiemetics & Analgesics & Antiemetics & Analgesics & Antiemetics \\
\hline 0 & $2(3.3)$ & 0 & $5(8.1)$ & 0 & 0.440 & - \\
\hline 0.5 & $3(5.0)$ & 0 & $7(11.3)$ & 0 & 0.323 & - \\
\hline 2 & $3(5.0)$ & $2(3.3)$ & $7(11.3)$ & 0 & 0.323 & 0.240 \\
\hline 8 & $2(3.3)$ & $1(1.7)$ & $7(11.3)$ & 0 & 0.164 & 0.492 \\
\hline 24 & $5(8.3)$ & $2(3.3)$ & $5(8.1)$ & 0 & 1.000 & 0.240 \\
\hline 48 & $3(5.0)$ & $2(3.3)$ & $4(6.5)$ & 0 & 1.000 & 0.240 \\
\hline
\end{tabular}

Values are presented as number of patients (\%). $P<0.05$ between the two groups. Group F, fentanyl group; Group 0, oxycodone group. 
Table 5. Patient satisfaction at 2- and 48 hours postoperatively

\begin{tabular}{lccc}
\hline Time after surgery & Group F $(n=60)$ & Group O (n=62) & P-value \\
\hline $2 \mathrm{hr}$ & & & 0.813 \\
Very satisfied & $6(10.0)$ & $6(9.7)$ & \\
Satisfied & $40(66.7)$ & $37(59.7)$ & \\
Neutral & $13(21.7)$ & $17(27.4)$ & \\
Dissatisfied & $1(1.7)$ & $2(3.2)$ & 0.621 \\
$48 \mathrm{hr}$ & & & \\
Very satisfied & $13(21.7)$ & $18(29.0)$ & \\
Satisfied & $40(66.7)$ & $35(56.5)$ & \\
Neutral & $5(8.3)$ & $5(8.1)$ & \\
Dissatisfied & $2(3.3)$ & $4(6.5)$ & \\
\hline
\end{tabular}

Values are presented as number of patients $(\%)$.

Group F, fentanyl group; Group 0, oxycodone group.

for pain control. However, there may be a clinical ceiling effect due to side effects including sedation, and especially respiratory depression [2]. Fentanyl has desirable properties as an IV-PCA drug, including very high lipid solubility, a rapid onset of analgesic effect (within 30 seconds) with a peak at 5 minutes after administration, rapid and widespread redistribution inside the body, and no production of active metabolites that can cause respiratory depression $[2,13]$.

Oxycodone is a semi-synthetic opioid developed in 1916 in Germany with the goal of improving the performance of opioids [7]. In addition, it has structural similarity to morphine, which is the standard opioid used worldwide, and shows an analgesic effect against a combination of somatic and visceral pain after surgery at a conversion dose ratio of 1:1 [14]. Since oxycodone is metabolized in the cytochrome P450 enzyme system in the liver and acts on the $\mu$-opioid receptor, it can cause side effects such as nausea, constipation, drowsiness, vomiting, pruritus, and dizziness, similar to other opioids [7].

The analgesic effects of opioids are related to plasma concentrations. The minimum effective concentration (MEC) or minimum effective analgesic concentration (MEAC) is typically used to explore the relationship between concentration and effect. The MEC represents the plasma concentration at the time when a patient requests re-medication due to severe pain, whereas the MEAC represents the drug concentration at that time. Wide inter- and intrasubject variability exists in the relationship between opioid dose, serum concentration, and analgesic response in the treatment of postoperative pain [15]. In addition, the severity of postoperative pain may vary depending on the type and method of surgical procedure, or depending on the surgical site even when the same sur- gical approach is used; patient pain can also differ over time. Thus, it is difficult to determine a 'one-size-fits-all' approach for pain control. However, it may be possible to develop a more effective pain control method if we identify the level of postoperative pain and amount of analgesic required after each surgery.

Kokki et al. [16] performed a study on 28 young patients who underwent laparoscopic cholecystectomy, showing that the MEAC of IV oxycodone was 45-50 ng/mL. However, two of the patients showed only mild pain and did not require additional administration after the $0.1 \mathrm{mg} / \mathrm{kg}$ bolus oxycodone, whereas four patients could not achieve an adequate analgesic effect even after the administration of 16-20 mg of oxycodone. In conclusion, the MEAC of IV-oxycodone was $24-88 \mathrm{ng} / \mathrm{mL}$, indicating a relatively high level of interindividual variation.

Oxycodone should be diluted to a concentration of $1 \mathrm{mg} / \mathrm{mL}$ when used for IV-PCA; the loading dose of $2 \mathrm{mg}$ should be administered to stabilize pain, after which $1 \mathrm{mg}$ is administered as necessary without background infusion. However, Choi [6] reported that because the administration of $2 \mathrm{mg} / \mathrm{kg}$ reached a plasma concentration below the MEAC, injection at a concentration of 0.1 $\mathrm{mg} / \mathrm{kg}$ may be more appropriate, and also noted that background infusion at a rate of $1 \mathrm{~mL} / \mathrm{hr}$ could reach the MEAC most rapidly. In this study, a loading dose of $7.5 \mathrm{mg}$ (which is higher than $0.1 \mathrm{mg}$ per $\mathrm{kg}$ ) was administered because the results of our previous study showed that when a $7.5 \mathrm{mg}$ bolus dose of oxycodone was injected after surgery we achieved an average NRS of 30 or higher 30 minutes after surgery [17]. Thus, the same amount, or a higher dose, of oxycodone should be administered. The loading dose of fentanyl was $150 \mathrm{mcg}$ with a conversion dose of 1:50, and the NRS immediately after surgery was below 30 , which was lower than that for oxycodone, indicative of a satisfactory analgesic effect (Fig. 3). Although there was no significant difference between the two groups 2 or more hours after surgery, the fentanyl-based IV-PCA showed a higher level of NRS than the oxycodone-based IV-PCA. These results were in contrast with previous studies showing that a conversion dose of 1:75 between fentanyl and oxycodone may be appropriate $[8,9]$. In previous studies, only the bolus dose was given for IV-PCA without continuous background infusion. However, when administration is via IV-PCA with continuous background infusion for several days, it is important to consider differences in pharmacokinetics between the two agents. Oxycodone has an onset time of analgesia of 2-3 minutes, which is as fast as fentanyl, but with a slightly longer duration of action (t1/2: 4 hours 
52 minutes versus 3 hours 39 minutes). However, after a single dose of fentanyl was injected, the analgesic effect showed a shorter duration due to redistribution [9]. Therefore, there was no significant difference at the 1:50 conversion dose between fentanyl and oxycodone, but the NRS score started to decline from 2 hours after the operation when the effect of the bolus loading dose disappeared.

Kawamata et al. [18] reported an experimental incision model where primary hyperalgesia caused by sensitization of the primary afferent nociceptors due to incision started to decrease within 2 hours after incision, whereas secondary hyperalgesia, which causes pain around the incised area due to central hypersensitization started to decrease within 6 hours. This study showed a significant decrease in NRS scores starting from 2 hours after surgery, which was due to a very small incision size. Therefore, pain control is the most important priority until 2 hours after surgery, but as the severity of pain was significantly decreased at 2 hours after surgery, other side effects including PONV should be considered. In this study, two patients discontinued PCA due to PONV.

Eberhart et al. [1] reported that PONV (49\%) was a more important patient concern than pain (27\%), which was common after surgery. PONV can increase medical costs and morbidity, and delay recovery and discharge; in severe cases, it can lead to readmission [19]. Risk factors for PONV include female gender, nonsmoking, a medical history of PONV, and use of opioids during and after surgery. It has been reported that if a patient has one risk factor, the incidence rate of PONV is $21 \%$; with two risk factors, it rises to $39 \%$; with three high risk factors, the incidence is $61 \%$ and with four it is 79\% [20]. Prophylactic anti-emetics are recommended for high-risk patients, and we administered dexamethasone 5 mg IV as a prophylactic anti-emetic agent at the beginning of the operation and added ramosetron $0.3 \mathrm{mg}$ after surgery. In this study, because we administered prophylactic anti-emetics and used an appropriate opioid, both groups showed a PONV incidence rate of less than $15 \%$, although they were high-risk patients (Table 2).

When the patients were surveyed based on patient satisfaction after surgery, there was no significant difference at 2 or 48 hours after surgery between the groups (Table 5); they showed a similar analgesic effect and side effects at a 1:50 conversion dose of fentanyl and oxycodone.

The limitations of this study were as follows: first, although the Ambix Anapa, a PCA machine used at our hospital, has several advantages, i.e., it is small, lightweight, and easy to carry, because background continuous infusion at a rate $2 \mathrm{~mL} / \mathrm{hr}$ and a bolus dose of $0.5 \mathrm{~mL}$ with a lockout interval of 15 minutes were established, patients were not guaranteed autonomy in terms of pain control. Also, there was no way to confirm the delivery attempt ratio and it was not possible to calculate an the equianalgesic dose of fentanyl and oxycodone accurately. Second, patient age is an important factor affecting the pharmacokinetics of oxycodone, and patients aged 70 years or more are reported to have a relatively higher average oxycodone exposure of $40 \%-80 \%$ compared to young adults [21]. As this targeted patients aged 65 years or less, more studies on patients aged 70 years or more are required. Last, the pain threshold may have differed among the patients, but no preliminary study was performed to explore this.

In conclusion, oxycodone showed similar effects, in terms of pain relief and side effects, compared to fentanyl when used at a conversion dose ratio of 50:1 after laparoscopic gynecologic surgery. Therefore, oxycodone may be useful as an alternative to fentanyl for IV-PCA after minor laparoscopic surgery.

\section{REFERENCES}

1. Eberhart LH, Morin AM, Wulf H, Geldner G. Patient preferences for immediate postoperative recovery. Br J Anaesth 2002;89:760-1.

2. Grass JA. Patient-controlled analgesia. Anesth Analg 2005;101(5 Suppl): S44-61.

3. Walder B, Schafer M, Henzi I, Tramer MR. Efficacy and safety of patientcontrolled opioid analgesia for acute postoperative pain: a quantitative systematic review. Acta Anaesthesiol Scand 2001;45:795-804.

4. Aarts JW, Nieboer TE, Johnson N, Tavender E, Garry R, Mol BW, et al. Surgical approach to hysterectomy for benign gynaecological disease. Cochrane Database Syst Rev 2015;(8):CD003677.

5. Gerbershagen HJ, Aduckathil S, van Wijck AJ, Peelen LM, Kalkman CJ, Meissner W. Pain intensity on the first day after surgery: a prospective cohort study comparing 179 surgical procedures. Anesthesiology 2013; 118:934-44.

6. Choi BM. A new therapeutic option for postoperative pain management with oxycodone HCI injection. Korean J Anesthesiol 2016;69:211-8.

7. Kalso E. Oxycodone. J Pain Symptom Manage 2005;29(5 Suppl):S47-56.

8. Hwang BY, Kwon JY, Kim E, Lee DW, Kim TK, Kim HK. Oxycodone vs. fentanyl patient-controlled analgesia after laparoscopic cholecystectomy. Int J Med Sci 2014;11:658-62.

9. Koch S, Ahlburg P, Spangsberg N, Brock B, Tonnesen E, Nikolajsen L. Oxycodone vs. fentanyl in the treatment of early post-operative pain after laparoscopic cholecystectomy: a randomised double-blind study. Acta Anaesthesiol Scand 2008;52:845-50.

10. Park JH, Lee C, Shin Y, An JH, Ban JS, Lee JH. Comparison of oxycodone and fentanyl for postoperative patient-controlled analgesia after laparoscopic gynecological surgery. Korean J Anesthesiol 2015;68:153-8.

11. Ding Z, Wang K, Wang B, Zhou N, Li H, Yan B. Efficacy and tolerability of oxycodone versus fentanyl for intravenous patient-controlled analgesia 
after gastrointestinal laparotomy: a prospective, randomized, double-blind study. Medicine (Baltimore) 2016;95:e4943.

12. Kim NS, Kang KS, Yoo SH, Chung JH, Chung JW, Seo Y, et al. A comparison of oxycodone and fentanyl in intravenous patient-controlled analgesia after laparoscopic hysterectomy. Korean J Anesthesiol 2015;68: 261-6.

13. Momeni M, Crucitti M, De Kock M. Patient-controlled analgesia in the management of postoperative pain. Drugs 2006;66:2321-37.

14. Silvasti M, Rosenberg P, Seppala T, Svartling N, Pitkanen M. Comparison of analgesic efficacy of oxycodone and morphine in postoperative intravenous patient-controlled analgesia. Acta Anaesthesiol Scand 1998;42: 576-80.

15. Kim JY, Park SY, Chang HS, Nam SK, Min SK. The efficacy of the timescheduled decremental continuous infusion of fentanyl for postoperative patient-controlled analgesia after total intravenous anesthesia. Korean J Anesthesiol 2013;65:544-51.

16. Kokki M, Broms S, Eskelinen M, Rasanen I, Ojanpera I, Kokki H. Analgesic concentrations of oxycodone: a prospective clinical PK/PD study in patients with laparoscopic cholecystectomy. Basic Clin Pharmacol Toxicol 2012;110:469-75.
17. Kim NS, Lee JS, Park SY, Ryu A, Chun HR, Chung HS, et al. Oxycodone versus fentanyl for intravenous patient-controlled analgesia after laparoscopic supracervical hysterectomy: a prospective, randomized, doubleblind study. Medicine (Baltimore) 2017;96:e6286.

18. Kawamata M, Watanabe H, Nishikawa K, Takahashi T, Kozuka Y, Kawamata T, et al. Different mechanisms of development and maintenance of experimental incision-induced hyperalgesia in human skin. Anesthesiology 2002;97:550-9.

19. Garg S, Subramani S, Sachdeva H. Postoperative nausea and vomiting: the achilles heel of anesthesiologists. J Anaesthesiol Clin Pharmacol 2017; 33:427-8.

20. Apfel CC, Laara E, Koivuranta M, Greim CA, Roewer N. A simplified risk score for predicting postoperative nausea and vomiting: conclusions from cross-validations between two centers. Anesthesiology 1999;91:693700.

21. Liukas A, Kuusniemi K, Aantaa R, Virolainen P, Neuvonen M, Neuvonen PJ, et al. Elimination of intravenous oxycodone in the elderly: a pharmacokinetic study in postoperative orthopaedic patients of different age groups. Drugs Aging 2011;28:41-50. 